\title{
COMPARAÇÃO DE MÉTODOS PARA DETECÇÃO DE Bipolaris sorokiniana EM SEMENTES DE CEVADA*
}

\author{
JAVIER TOLEDO BARBA ${ }^{1}$, ERLEI M. REIS ${ }^{2} \&$ CARLOS A. FORCELINI ${ }^{2}$
}

${ }^{1}$ Centro de Investigación Agrícola Tropical (CIAT), Santa Cruz, Bolívia; ${ }^{2}$ Faculdade de Agronomia e Medicina Veterinária, Universidade de Passo Fundo, Cx. Postal 611, 99001-970, Passo Fundo, RS

(Aceito para publicação em 14/05/2002)

Autor para correspondência: Erlei Melo Reis

TOLEDO, J., REIS, E.M. \& FORCELINI, C.A. Comparação de métodos para detecção de Bipolaris sorokiniana em sementes de cevada. Fitopatologia brasileira 27:389-394. 2002.

\section{RESUMO}

O fungo Bipolaris sorokiniana, agente causal da helmintosporiose da cevada (Hordeum vulgare), sobrevive como micélio em sementes infetadas e saprofiticamente nos restos culturais de seus hospedeiros. Em experimentos conduzidos em laboratório, diferentes métodos [papel-filtro, papel-filtro + componentes líquidos do meio seletivo de Reis (MSR), batatadextrose-ágar (BDA), extrato de tomate-ágar, V-8-ágar, meio seletivo de Reis (MSR) e meio seletivo de Dodman \& Reinke] foram comparados visando selecionar o mais sensível para detecção de $B$. sorokiniana em sementes de cevada. Os meios foram testados com e sem congelamento das sementes. Sem congelamento, os meios seletivos foram mais sensíveis na detecção de B. sorokiniana, seguidos pelo meio de BDA. O método papel-filtro padrão ocupou uma posição intermediária, estatisticamente inferior aos demais. Sob congelamento a $-20{ }^{\circ} \mathrm{C}$ (durante $16 \mathrm{~h}$ ), o tratamento térmico anulou o efeito dos substratos na detecção do fungo, de tal modo que todos apresentaram comportamento estatisticamente semelhante. Esse procedimento não afetou positivamente a detecção do fungo-alvo deste estudo. O meio seletivo de Reis foi mais sensível que o de papel-filtro + congelamento na detecção de $B$. sorokiniana em sementes com diferentes níveis de incidência.

Palavras-chave adicionais: Hordeum vulgare, patologia de sementes, análise, helmintosporiose.

\section{ABSTRACT \\ Comparison of methods for the detection of Bipolaris sorokiniana in barley seeds}

The fungus Bipolaris sorokiniana, the causal agent of the brown spot of barley (Hordeum vulgare), survives as mycelium in infected seeds or saprofiticaly on host plant debris. In lab experiments, various methods for seed testing [blotter test; blotter test + liquid components of the Reis selective medium; PDA medium; tomato paste medium; V-8 medium; Reis selective medium, and the Dodman \& Reinke selective medium] were compared regarding the detection of $B$. sorokiniana in barley seeds. The selective media, especially the Reis medium, were more sensitive than the PDA and the blotter tests. Seed freezing $\left(-20^{\circ} \mathrm{C}\right.$ for $16 \mathrm{~h}$ ) prior to incubation did not improve the fungus detection and determined similar results for all methods.

\section{INTRODUÇÃO}

Sementes de cevada (Hordeum vulgare L.), frequientemente, encontram-se infetadas por fungos patogênicos como Bipolaris sorokiniana (Sacc.) Shoem., Drechslera teres (Sacc.) Shoem. e Fusarium graminearum Schwabe, agentes causais de doenças que limitam a produtividade dessa cultura no sul do Brasil, especialmente nos Estados do Rio Grande do Sul, Santa Catarina e Paraná.

Através das sementes infetadas, fungos como $B$. sorokiniana são introduzidos em áreas novas de cultivo ou em lavouras sob rotação de culturas, sendo posteriormente transmitidos para os órgãos radiculares (mesocótilo e raízes seminais) e aéreos (coleóptilo e plúmula). No trigo (Triticum

\footnotetext{
* Parte da Dissertação de Mestrado do primeiro autor. Universidade de Passo Fundo (2001)
}

aestivum L.), estudos sobre a eficiência de transmissão desse fungo relatam valores de até $88 \%$ ao coleóptilo (Reis \& Forcelini, 1993), 68\% ao mesocótilo (Forcelini, 1992) e 38\% à plúmula (Toledo et al., 1996). Por causa da elevada transmissão que B. sorokiniana apresenta, Reis (1987) considera que o controle desse fungo deve ser orientado à erradicação na semente a fim de reduzir o inóculo primário na lavoura. Para isso, torna-se necessário contar com métodos de detecção mais sensíveis que permitam revelar o máximo de incidência do patógeno, proporcionando maior precisão na quantificação do fungo veiculado pela semente, sobretudo quando se trata de testes de eficácia de fungicidas ou outros métodos de erradicação.

Entre os vários métodos disponíveis para detecção de fungos em sementes, os testes com papel de filtro são os mais conhecidos e utilizados, dentre os quais se destaca o de congelamento (Neergaard, 1973). Esse método é o mais 


\section{J.T. Barba et al.}

amplamente usado nos testes rotineiros de sanidade de sementes (Mathur, 1983; Neergaard, 1983), embora a incidência de muitos fungos e bactérias contaminantes, que crescem rapidamente neste substrato, possa impedir a frutificação dos fungos-alvo, dificultando a sua identificação e quantificação, sobretudo os de crescimento lento. Nesse último caso, a incidência pode ser subestimada (Tempe, 1970; Neergaard, 1973; Reis et al., 1999).

O desenvolvimento de meios seletivos ou semiseletivos para a detecção de conídios dormentes de $B$. sorokiniana no solo (Kulkarni et al., 1978; Dodman \& Reinke, 1982; Reis, 1983; Filippova \& Kashemirova, 1990) tem aberto a possibilidade de seu uso na detecção desse fungo em análises rotineiras de patologia de sementes, como concluem e recomendam Reis et al. (1999).

O presente trabalho teve por objetivo comparar e avaliar diferentes meios de cultura e métodos usados em laboratório, com a finalidade de selecionar o mais sensível na detecção de B. sorokiniana associado a sementes de cevada.

\section{MATERIAL E MÉTODOS}

Os trabalhos foram conduzidos no Laboratório de Fitopatologia da Faculdade de Agronomia e Medicina Veterinária da Universidade de Passo Fundo, RS, no período de dezembro/2000 a fevereiro/2001. Considerando-se o número de tratamentos e o tempo requerido nas avaliações, optou-se por conduzir o trabalho em dois experimentos: a) semente sem congelamento e b) semente com congelamento. Cada experimento foi desenvolvido com lotes de sementes diferentes.

Cada experimento constou de sete métodos de detecção, empregando-se sementes de cevada da cultivar BR-2, naturalmente infetadas com $B$. sorokiniana. Os métodos comparados foram: 1) papel-filtro (Tempe, 1970); 2) papelfiltro + componentes líquidos do meio seletivo de Reis - MSR (Reis, 1983); 3) meio batata-dextrose-ágar (BDA) (preparado de acordo com Fernandez, 1993); 4) meio extrato-tomateágar (Fernandez, 1993); 5) meio V-8-ágar (Fernandez, 1993); 6) meio seletivo de Reis (Reis, 1983); e 7) meio seletivo de Dodman \& Reinke modificado (Dodman \& Reinke, 1982).

O método 2 (papel-filtro + MSR) utilizou uma solução composta por estreptomicina $(0,5 \mathrm{~g})$ dissolvida em $50 \mathrm{ml}$ de água destilada esterilizada (ADE), neomicina $(0,3 \mathrm{~g})$ em 50 $\mathrm{ml}$ de ADE, benomil (0,06 g) em $32 \mathrm{ml}$ de ADE, botram ( 5 $\mathrm{ml}$ de suspensão estoque) e captam ( $3 \mathrm{ml}$ de suspensão estoque), em um volume total de $140 \mathrm{ml}$. Desta suspensão final, pipetou-se uma alíquota de $3,5 \mathrm{ml}$ por placa de Petri contendo três discos de papel-filtro (total de placas: 40 ). O mesmo volume foi empregado no método 1 (3,5 $\mathrm{ml}$ de água destilada esterilizada/placa).

Os meios seletivos sofreram algumas modificações. $\mathrm{O}$ MSR teve sua quantidade de benomil incrementada de 0,05 para 0,06 g. No meio de Dodman \& Reinke (1982), o hidrocloreto de clorotetraciclina e o captafol foram substituídos por hidrocloreto de tetraciclina e por captam. Para os métodos
3, 4 e 5, usou-se $0,2 \mathrm{~g}$ de sulfato de estreptomicina por litro de meio.

No experimento semente sem congelamento, as mesmas foram plaqueadas de forma eqüidistante, mediante o uso de pinça esterilizada. Previamente, as sementes foram desinfestadas com hipoclorito de sódio $0,5 \%$, durante $3 \mathrm{~min}$. Os trabalhos foram realizados em câmara de isolamento de fluxo laminar, principalmente para os métodos 3, 4 e 5 . Utilizaram-se dez sementes por placa. Após o plaqueamento, as placas de Petri ( $9 \mathrm{~cm}$ de diâmetro) foram vedadas com papel parafinado ("parafilm") para evitar a perda de umidade durante a incubação. Cada tratamento constou de quatro repetições. A seguir, as sementes foram incubadas em câmara de crescimento com fotoperíodo de $12 \mathrm{~h}$ e temperatura de 25 $\pm 2{ }^{\circ} \mathrm{C}$.

No experimento semente com congelamento, estas foram desinfestadas com hipoclorito de sódio a $0,5 \%$, por 3 min, e plaqueadas de forma equiidistante em caixas gerbox contendo três folhas de papel-filtro esterilizadas, umedecidas com $7 \mathrm{ml}$ de ADE, onde foram acondicionadas 100 a 120 sementes. Nessas condições, as sementes foram mantidas em câmara de crescimento com fotoperíodo de $12 \mathrm{~h}$ e temperatura de $25 \pm 2{ }^{\circ} \mathrm{C}$ durante $24 \mathrm{~h}$, para induzir a germinação. Após esse período, as sementes foram congeladas a $-20 \pm 1{ }^{\circ} \mathrm{C}$, por $16 \mathrm{~h}$, para interromper a germinação, segundo a metodologia empregada por Pryor et al. (1994). Transcorrido esse período, as sementes foram plaqueadas com ajuda de uma pinça esterilizada (flambada cada vez que se tomava uma semente), para os diferentes métodos de detecção testados, sendo as placas vedadas com "parafilm". Em cada placa de Petri foram colocadas dez sementes. Cada tratamento constou de quatro repetições.

Em ambos os experimentos, o tempo de incubação variou em função do método usado: cinco dias para os métodos extrato de tomate-ágar e V-8-ágar; sete dias para BDA; oito dias para papel-filtro e papel-filtro + MSR; onze dias para os meios seletivos. Finalizado o período de incubação, as sementes e/ou as colônias desenvolvidas foram examinadas sob microscópio estereoscópio para a identificação do fungo através da observação das suas estruturas reprodutivas. Foram consideradas infetadas as sementes com conidióforos e conídios de B. sorokiniana, conforme descrição por Ellis (1971)

Em função dos resultados obtidos nos dois experimentos anteriores e com a finalidade de estudar o possível efeito do congelamento $\left(-20^{\circ} \mathrm{C}\right)$ na detecção de $B$. sorokiniana na semente, planejou-se um terceiro experimento, no qual se compararam quatro métodos ou tratamentos: 1) papel-filtro; 2) meio seletivo de Reis; 3) papel-filtro + congelamento; e 4) meio seletivo de Reis + congelamento. Neste experimento, foram conduzidos dois ensaios: o primeiro com sementes de cevada (cultivar BR-2) com incidência de B. sorokiniana inferior a 20\%; o segundo com sementes de trigo (cultivar Sonalika) com incidência de B. sorokiniana superior a $70 \%$. O período de incubação foi de dez dias para todos os tratamentos. Cada tratamento constou de cinco repetições. 
Nos três experimentos, o delineamento experimental empregado foi o de tratamentos inteiramente casualizados. Para cada método, empregaram-se 100 sementes por repetição, distribuídas em dez placas. Os dados obtidos foram expressos em percentagem de sementes infetadas com B. sorokiniana, sendo submetidos à análise de variância $(\mathrm{P}<0,05)$, comparando-se as médias pelo teste de Tukey $(5 \%)$ e por contrastes ortogonais a $5 \%$ de probabilidade (terceiro experimento).

\section{RESULTADOS E DISCUSSÂO}

A incidência de $B$. sorokiniana em sementes de cevada foi afetada significativamente pelos diferentes métodos de detecção que não envolveram congelamento das sementes. Por outro lado, nas sementes submetidas ao congelamento, os métodos comparados não evidenciaram diferenças estatísticas entre si (Tabela 1).

Pelos resultados expressos na Tabela 1, é possível deduzir que os métodos de incubação que utilizaram meios seletivos (métodos 6 e 7) foram os mais sensíveis na detecção de B. sorokiniana (43 e 42,75\% de incidência), sem diferenças estatísticas entre si. O meio BDA (incidência de 38,5\%) evidenciou um comportamento estatisticamente similar aos meios seletivos, ao passo que os métodos V-8-ágar, extrato de tomate-ágar e papel-filtro foram menos eficazes. O método de papel-filtro + MSR (método 2) demonstrou ser o menos sensível, pois nele se detectou a menor incidência do fungo.

Diante dos resultados apresentados (Tabela 2) observase diferença estatística $(\mathrm{P}<0,05)$ apenas no ensaio com sementes de cevada que apresentaram incidência baixa do fungo. Neste ensaio, segundo a análise de contrastes ortogonais, os métodos com papel-filtro (com e sem congelamento) mostraram-se estatisticamente inferiores aos métodos com o

TABELA 1 - Incidência média de Bipolaris sorokiniana em sementes de cevada (Hordeum vulgare) analisadas por diferentes métodos de sanidade, sem ou com congelamento

\begin{tabular}{lcc}
\hline & \multicolumn{2}{c}{ Incidência (\%) } \\
\cline { 2 - 3 } Método & $\begin{array}{c}\text { Experimento } \mathbf{1}^{\mathbf{1}} \\
\text { Sem } \\
\text { congelamento }\end{array}$ & $\begin{array}{c}\text { Experimento 2 } \\
\text { Com } \\
\text { congelamento }\end{array}$ \\
\hline 1. Papel-filtro & $28,25 \mathrm{c}^{\mathbf{5}}$ & $15,25 \mathrm{a}$ \\
2. Papel-filtro + MSR ${ }^{2}$ & $13,75 \mathrm{~d}$ & $12,25 \mathrm{a}$ \\
3. Batata-dextrose-ágar ${ }^{3}$ & $38,50 \mathrm{ab}$ & $15,25 \mathrm{a}$ \\
4. Extrato-tomate-ágar ${ }^{3}$ & $30,50 \mathrm{bc}$ & $15,50 \mathrm{a}$ \\
5. V-8-ágar ${ }^{3}$ & $32,25 \mathrm{bc}$ & $16,75 \mathrm{a}$ \\
6. M.S. de Reis & $43,00 \mathrm{a}$ & $16,50 \mathrm{a}$ \\
7. M.S. de Dodman \& Reinke & $42,75 \mathrm{a}$ & $18,00 \mathrm{a}$ \\
\hline C.V. (\%) & 12,46 & 17,37 \\
D.M.S. (5\%) & 5,99 & 3,99 \\
\hline
\end{tabular}

${ }^{1}$ Experimentos desenvolvidos com lotes de sementes diferentes (cv. BR-2).

${ }^{2}$ Papel-filtro + componentes líquidos do meio seletivo de Reis.

${ }^{3}$ Meio de cultura $+0,2 \mathrm{~g}$ de sulfato de estreptomicina.

${ }^{4}$ M.S. = meios seletivos para recuperar B. sorokiniana do solo.

${ }^{5}$ Médias seguidas por letras distintas na vertical diferem entre si pelo teste de Tukey (5\%).
MSR (com e sem congelamento). Por outro lado, entre os tratamentos com e sem congelamento do papel-filtro e do MSR em separado, não foi possível encontrar diferenças estatísticas para nenhuma das comparações.

No caso do ensaio com sementes de trigo (incidência alta do fungo), a análise de contrastes ortogonais evidenciou que os métodos com papel-filtro (com e sem congelamento) não diferiram do MSR (com e sem congelamento). O efeito do congelamento foi significativo apenas no método do papelfiltro, resultando em maior detecção do fungo.

Quando, em análise patológica das sementes, objetivase detectar a presença de patógenos específicos, o emprego de meios seletivos ou semi-seletivos torna-se uma ferramenta de grande valor para o fitopatologista, pois evita o desenvolvimento de contaminantes, favorecendo a detecção e a identificação do patógeno-alvo (Richardson, 1985). Essa eficiência foi refletida nos resultados do experimento sem congelamento (Tabela 1), no qual os meios seletivos MSR (Reis, 1983) e de Dodman \& Reinke (1982) foram os mais sensíveis na detecção de $B$. sorokiniana. Em trabalhos de similar envergadura, Reis et al. (1999) não encontraram diferença estatisticamente significativa entre o método do papel-filtro tradicional recomendado pelo ISTA (Neergaard, 1973) e o MSR na detecção do fungo em sementes de trigo, sendo esses, segundo os autores, os métodos mais sensíveis para a detecção de B. sorokiniana.

Quanto ao meio BDA, que manifestou um comportamento estatisticamente similar aos meios seletivos, é importante salientar que esse desempenho pode ser inferior quando ocorrer a presença de contaminantes de crescimento rápido, como Trichoderma spp., Rhizopus spp., Mucor spp. e Fusarium spp. Esses fungos podem, em pouco tempo, cobrir completamente a placa de Petri, dificultando a identificação

TABELA 2 - Incidência média de Bipolaris sorokiniana a partir de sementes de cevada (Hordeum vulgare) e trigo (Triticum aestivum) analisadas por diferentes métodos de sanidade

\begin{tabular}{|c|c|c|}
\hline \multirow{2}{*}{ Método } & \multicolumn{2}{|c|}{ Incidência (\%) } \\
\hline & Cevada $^{1}$ & Trigo $^{2}$ \\
\hline 1. Papel-filtro sem congelamento & 9,2 & 72,2 \\
\hline 2. Meio seletivo de Reis sem congelamento & 14,4 & 75,2 \\
\hline 3. Papel-filtro com congelamento & 9,6 & 78,0 \\
\hline 4. Meio seletivo de Reis com congelamento & 12,0 & 78,2 \\
\hline C.V. $(\%)$ & 22,91 & 5,25 \\
\hline D.M.S. (5\%) & 3,47 & 5,34 \\
\hline Contrastes ortogonais & Erro & $\mathbf{F}$ \\
\hline \multicolumn{3}{|l|}{ Cevada } \\
\hline $1+3$ vs. $2+4$ & 0,579 & $10,78 * *$ \\
\hline 1 vs. 3 & 0,819 & 0,06 n.s \\
\hline 2 vs. 4 & 0,819 & 2,15 n.s. \\
\hline \multicolumn{3}{|l|}{ Trigo } \\
\hline $1+3$ vs. $2+4$ & 0,892 & 0,81 n.s. \\
\hline 1 vs. 3 & 1,261 & $5,29 *$ \\
\hline 2 vs. 4 & 1,261 & 1,42 n.s. \\
\hline
\end{tabular}

${ }^{1}$ Cultivar BR-2.

${ }^{2}$ Cultivar Sonalika. 


\section{J.T. Barba et al.}

e detecção do fungo-alvo, principalmente quando a semente não for desinfestada. Esses inconvenientes podem ser ainda mais acentuados quando são empregados substratos mais nutritivos, como os meios de extrato tomate-ágar e V-8-ágar.

No caso dos métodos em que foi empregado o papelfiltro como substrato (métodos 1 e 2), observou-se um baixo nível de esporulação na semente. Esse fato dificultou e retardou a avaliação, situação que foi ainda mais acentuada no método em que se combinou o papel-filtro com os componentes líquidos do MSR. Além do inconveniente anteriormente citado, acrescenta-se o problema da formação de conídios com morfologia alterada (mais fusiformes) e coloração menos escura (ligeiramente hialinos). Essas alterações morfológicas dificultaram a identificação do fungo e, possivelmente, a sua quantificação. As alterações podem ter sido causadas pelos fungicidas e, talvez, pelos antibióticos usados no meio de cultura, que podem ter sido fungitóxicos a B. sorokiniana.

Em função do exposto anteriormente, é possível deduzir que tanto os meios seletivos (especialmente o MSR) como o meio BDA poderiam ser usados rotineiramente nos testes de patologia de sementes de cevada, porém, considerando que o preparo dos meios seletivos exige muito tempo e demanda reagentes nem sempre disponíveis, o meio BDA seria o mais adequado para tal finalidade. Deve-se salientar que o emprego dos meios seletivos desempenharia um papel importante em trabalhos de controle químico, especialmente quando se objetiva erradicar o patógeno da semente, situação em que a sua sensibilidade e seletividade teriam um papel preponderante, considerando que se trabalha com níveis de incidência muito baixos.

No experimento em que a semente foi submetida ao congelamento (Tabela 1), não se detectou diferença estatística entre os métodos. Essa situação pode ser atribuída à inibição da germinação da semente, pois, mediante esse procedimento, foi possível obter um maior contato da semente com o substrato, ao evitar o desenvolvimento da plúmula e de raízes que, de uma ou outra maneira, podem inibir ou dificultar o desenvolvimento e observação do patógeno. Esse melhor contato entre a semente e o substrato pode ter criado condições mais favoráveis, especialmente de umidade (presença de água líquida na superfície da semente), o que estimulou a esporulação do fungo, facilitando, desse modo, a sua rápida detecção e quantificação, como mencionam Neergaard (1983) e Machado (1988).

Um aspecto negativo observado em todos os métodos com congelamento foi a proliferação de bactérias, também reportado por Tempe (1970). Esse autor menciona que o excesso de água no substrato (papel-filtro) pode reduzir a incidência de alguns patógenos, efeito inicialmente relacionado ao antagonismo provocado por bactérias. Esse aspecto não se encontra diretamente relacionado com o observado neste trabalho, pois a proliferação de bactérias foi detectada em todos os métodos testados. Com relação ao volume de água empregado por placa de Petri (3,5 ml/placa), nos métodos com papel-filtro, foi verificada difença daquele determinado por Kolk \& Karlberg (apud Neergaard, 1973), os quais demonstraram que, para $B$. sorokiniana, o volume ótimo é de $25 \mathrm{ml}$ por disco de papel-filtro, acondicionados em placas de Petri de $17 \mathrm{~cm}$ de diâmetro e $4 \mathrm{~cm}$ de altura. Porém, o volume empregado mostra mais relação com o volume de água (5,25 a 5,75 ml) estabelecido por Jørgensen (1982a) para trabalhos de quantificação de Pyrenophora graminea Ito \& Kurib. e P. teres (Sacc.) Shoem.

Um aspecto positivo que deve ser salientado nos resultados observados no método de congelamento foi a formação de colônias características, facilmente diferenciáveis do fungo, permitindo maior eficiência na sua detecção e quantificação. Por outro lado, os meios que favoreceram um rápido desenvolvimento de colônias típicas foram os mais nutritivos, como o extrato de tomate-ágar e o V-8-ágar, que apresentaram colônias maiores $(2-4 \mathrm{~cm}$ de diâmetro em cinco dias de incubação) e uma maior taxa de crescimento (> $9 \mathrm{~mm} /$ dia). Quanto à coloração nesses substratos, as colônias apresentaram centro de cor preto-cinza, com anéis concêntricos difusos (abundante esporulação) e bordas esbranquiçadas, sendo mais proeminente no meio V-8-ágar.

No caso do BDA, as colônias desenvolvidas mostraram características visuais semelhantes às descritas anteriormente, mas diferenciaram-se por apresentarem taxas de crescimento inferiores a $9 \mathrm{~mm} / \mathrm{dia}$, o que permitiu manter o processo de incubação por mais tempo (sete dias).

Nos meios em que foi empregado o papel-filtro como substrato, as sementes desenvolveram colônias pretas ou ligeiramente cinza e com anéis concêntricos sobre o papel (abundante esporulação), sobretudo no papel-filtro + água, corroborando o reportado por Garrett (1980). Algo singular foi observado na combinação papel-filtro + MSR, na qual as colônias apresentaram-se mais claras que no papel-filtro + água, com coloração rosada em alguns casos.

Nos meios seletivos, MSR e de Dodman \& Reinke (1982), o desenvolvimento das colônias foi lento, com taxa de crescimento inferior a $1 \mathrm{~mm} / \mathrm{dia}$. Porém, isso não representou nenhum inconveniente, pois a seletividade que os meios evidenciaram não permitiu o desenvolvimento de outros fungos que pudessem interferir na identificação e quantificação de B. sorokiniana, excetuando-se Alternaria spp., Bipolaris spp., Curvularia spp. e Drechslera spp.

Para caracterizar as colônias desenvolvidas nos meios seletivos, foi necessário incubá-las por períodos de tempo superiores a 20 - 30 dias. No caso do meio de Dodman \& Reinke (1982), as colônias apresentaram anéis marcadamente diferenciáveis, de coloração completamente preta (abundante esporulação) e pouco (na parte central) ou nenhum crescimento vegetativo superficial na parte central mas sim, internamente no substrato, contrastando com a cor do meio. Colônias no MSR mostraram uma coloração pretoavermelhada com a presença de tufos branco-rosa na parte central da colônia.

Em vista dos resultados obtidos em ambos os ensaios do terceiro experimento, deduz-se que o processo de congelamento a $-20{ }^{\circ} \mathrm{C}$ não afetou significativamente a 
detecção do fungo na semente. De modo igual, Duczek (1995) concluiu que o congelamento $\left(-18{ }^{\circ} \mathrm{C}\right)$ não afetou a sobrevivência do fungo em colmos de trigo naturalmente infetados, mas reduziu sua esporulação.

O MSR demonstrou ser sensível e eficiente na detecção de B. sorokiniana, tanto em níveis altos como em níveis relativamente baixos de incidência do fungo na semente, ao passo que o comportamento do papel-filtro tende a ser variável. É importante salientar que o fato de se ter trabalhado com um número reduzido de amostras e, sobretudo, com sementes de diferentes espécies (cevada e trigo) pode ter influenciado os resultados, segundo o relato de Jørgensen (1982b). Contudo, trabalhos desenvolvidos por Da Silva (1998), Lângaro (1998) e Reis et al. (1999) corroboram os resultados obtidos no presente trabalho. Por outro lado, quanto ao papel-filtro + congelamento, diversos estudos reportam a sua maior eficiência na detecção de $B$. sorokiniana e de outros fungos com relação ao papel-filtro padrão (Lasca et al., 1987).

Em geral, tanto o MSR como o papel-filtro + congelamento apresentaram-se vantajosos quanto à eficiência de detecção e quantificação de B. sorokiniana em sementes, pois facilitaram a visualização das estruturas do fungo. No caso do MSR, a presença de abundante esporulação de cor preta na superfície da semente e nas raízes seminais, ou a presença de micélio marrom-avermelhado na parte inferior da semente (parte que entra em contato com o meio) ou nos extremos das raízes que estavam em contato com o meio, facilitaram a detecção rápida do fungo. $\mathrm{O}$ mesmo fato ocorreu quando se empregou papel-filtro + congelamento. Porém, devido a esse último substrato não ser seletivo, o crescimento rápido de fungos como Fusarium spp. pode cobrir completamente a semente, formando colônias sobre o papel e interferindo na detecção de B. sorokiniana. Nesse caso, é necessário virar completamente a semente para examiná-la, especialmente quando a sutura fica em contato com o papel, para se ter certeza de que não ocorre nenhuma esporulação do fungo.

Por último, é importante salientar que outros meios seletivos reportados na literatura (Kulkarni et al., 1978; Filippova \& Kashemirova, 1990), além dos comparados no presente experimento, poderiam proporcionar uma base científica para futuros trabalhos na área da sanidade de sementes de cereais, cujo objetivo principal seja a detecção de fungos dematiáceos como os dos gêneros Bipolaris, Drechslera, Exserohilum, Alternaria e Curvularia, abrindo a possibilidade de serem utilizados com vantagem na detecção desses fungos em análise rotineira de patologia de sementes.

\section{REFERÊNCIAS BIBLIOGRÁFICAS}

DA SILVA, C.A.L. Detecção, transmissão e erradicação de Bipolaris sorokiniana, agente causal da helmintosporiose, em sementes de trigo. (Tese de Mestrado). Passo Fundo, RS. Universidade de Passo Fundo. 1998.

DODMAN, R.L. \& REINKE, J.R. A selective medium for determining the population of viable conidia of Cochliobolus sativus in soil. Australian Journal of Agricultural Research 33:287-291. 1982.

DUCZEK, L.J. Evidence of cold hardening in Bipolaris sorokiniana. Canadian Journal of Plant Pathology 17:342-345. 1995.

DUCZEK, L.J. \& WILDERMUTH, G.B. Effect of temperature, freezing period, and drying on the sporulation of Cochliobolus sativus on mature stem bases of wheat. Canadian Journal of Plant Pathology 14:130-136. 1992.

ELLIS, M.B. Dematiaceous Hyphomicetes. Kew, England. Commonwealth Mycological Institute (CAB). 1971.

FERNANDEZ, M.R. Manual para laboratório de fitopatologia. Documento 6. Embrapa-CNPT. Passo Fundo, RS. 1993.

FILIPPOVA, G.G. \& KASHEMIROVA, L.A. A culture medium for Bipolaris sorokiniana (Sacc.) Shoem. Mikologiya i Fitopatologiya 24:333-335. 1990.

FORCELINI, C.A. Incidência, transmissão e controle de Bipolaris sorokiniana em sementes de trigo. (Tese de Mestrado). Piracicaba, SP. ESALQ. 1992.

JØRGENSEN, J. The freezing blotter method in testing barley seed for inoculum of Pyrenophora graminea and P. teres. Repeatability of test results. Seed Science \& Technology 10:639-646. 1982a.

JØRGENSEN, J. The freezing blotter method in testing barley seed for inoculum of Pyrenophora graminea. Varietal resistance and predictive value of test results. Seed Science \& Technology 10:647-650. 1982b.

KHARCHENKO, S. \& SHKLYAR, V. Fungistatic properties of herbicides against some species of phytopathogenic fungi. Referativnyi Zhurnal 3:415. 1976.

KULKARNI, S., SIDDARAMAIAH, A.L. \& PRASAD, K.S.K. A selective medium for isolation of Drechslera sativum (Pam., King \& Bakke) Subram. \& Jain, from soil. Current Research 8:134-135. 1978.

LÂNGARO, N.C. Detecção, transmissão e controle de Drechslera avenae em sementes de aveia branca. (Tese de Mestrado). Passo Fundo, RS. Universidade de Passo Fundo. 1998.

LASCA, C. de C., VECHIATO, M.H. \& SCHMIDT, J.R. Seleção de métodos para detecção de Helminthosporium sativum em sementes de trigo (Triticum aestivum L.). Summa Phytopathologica 13:14. 1987. (Resumo).

MACHADO, J. da C. Patologia de sementes:fundamentos e aplicações. Lavras. ESAL/FAEPE. 1988.

MATHUR, S.B. Testing seeds of tropical species for seed-borne diseases. Seed Science \& Technology 11:113-128. 1983.

NEERGAARD, P. Detection of seed-borne pathogens by culture tests. Seed Science \& Technology 1:217-254. 1973.

NEERGAARD, P. Seed pathology. v.1. London. The Macmillan Press. 1983.

PRYOR, B.M,; DAVIS, R.M. \& GILBERTSON, R.L. Detection and eradication of Alternaria radicina on carrot seed. Plant Disease 78:452-456. 1994.

REIS, E.M. Selective medium for isolating Cochliobolus sativus from soil. Plant Disease 67:68-70. 1983.

REIS, E.M. Patologia de sementes de cereais de inverno. São Paulo, SP. CNDA. 1987.

REIS, E.M. \& CASA, R.T. Patologia de sementes de cereais de inverno. Passo Fundo, RS. Aldeia Norte. 1998.

REIS, E.M. \& FORCELINI, C.A. Transmissão de Bipolaris sorokiniana de sementes para órgãos radiculares e aéreos do trigo. Fitopatologia Brasileira 18:76-81. 1993.

REIS, E.M., REIS, A.C., CASA, R.T. \& BLUM, M.M.C. 
Comparison of methods to detect leaf and head blighting fungi in small grain seeds. Summa Phytopathologica 25:364-367. 1999.

TEMPE, J. de. Handbook on seed health testing:routine methods for determining the health condition of seed in the seed testing station. Proceeding of the International Seed Testing
Association. v.35. n ${ }^{\circ} 1.1970$.

TOLEDO, J., ROCA, R.H. \& ESCÓBAR, R.E. Transmisión, persistencia y control químico de Bipolaris sorokiniana causante de la punta negra del grano en trigo. In: CIAT. Informe Técnico. Proyecto de Investigación Trigo. Santa Cruz de la Sierra, Bolivia. 1996. pp. 87-106. 